\title{
Review Article \\ Thyroid Hormone Action in Cerebellum and Cerebral Cortex Development
}

\author{
Fabrice Chatonnet, Frédéric Picou, Teddy Fauquier, and Frédéric Flamant
}

Institut de Génomique Fonctionnelle de Lyon, Ecole Normale Supérieure de Lyon, Université de Lyon, UMR CNRS 5242, 46 allée d'Italie, 69364 Lyon Cedex 07, France

Correspondence should be addressed to Frédéric Flamant, frederic.flamant@ens-lyon.fr

Received 15 March 2011; Accepted 9 April 2011

Academic Editor: Juan Bernal

Copyright (C) 2011 Fabrice Chatonnet et al. This is an open access article distributed under the Creative Commons Attribution License, which permits unrestricted use, distribution, and reproduction in any medium, provided the original work is properly cited.

Thyroid hormones ( $\mathrm{TH}$, including the prohormone thyroxine ( $\mathrm{T} 4)$ and its active deiodinated derivative 3,3', 5 -triiodo-L-thyronine (T3)) are important regulators of vertebrates neurodevelopment. Specific transporters and deiodinases are required to ensure T3 access to the developing brain. T3 activates a number of differentiation processes in neuronal and glial cell types by binding to nuclear receptors, acting directly on transcription. Only few T3 target genes are currently known. Deeper investigations are urgently needed, considering that some chemicals present in food are believed to interfere with $\mathrm{T} 3$ signaling with putative neurotoxic consequences.

\section{What Is the Level of TH in the Brain?}

Congenital hypothyroidism causes mental retardation and has irreversible consequences if not treated soon after birth [1]. Routine testing of newborns allows a rapid diagnostic and permits to initiate a therapeutic intervention, $\mathrm{TH}$ supplementation, which usually restores most cognitive functions. However, iodine deficiency is still considered to be one of the most frequent causes of preventable mental retardation in children worldwide $[2,3]$, prompting to reinforce salt iodization in all countries [4]. Upon thyrotropin (TSH) stimulation, thyroid gland mainly secretes T4, which is deiodinated to produce T3. It is usual to assume that measuring TSH, T4, and T3 levels in blood is sufficient to estimate T3 level in brain. This is, however, ignoring that T3 access in brain is highly regulated. Furthermore, even after the onset of the fetal thyroid gland function, which occurs only at midgestation in humans, fetal brain relies on maternal TH. TH first cross the placenta [5] and then the brain-blood barrier. This transport is thought to favor T4 at the expense of T3 [6]. The predominant function of transport across the brain-blood barrier has been shown by using pregnant female rats, depleted of both maternal and fetal T4 and T3 $[6,7]$. In these conditions, administration of excess of T4 during the second half of gestation increases $\mathrm{T} 4$ and T3 levels in the maternal serum, and restores the T3 level in both fetal liver and fetal cortex. By contrast, maternal administration of T3 leads to a similar increase in T3 level for the fetal liver, implying its transport through the placenta, but to partial restoration of T3 level in fetal cortex. This confirms the importance of differential T4 and T3 transport, and outlines the requirement of local conversion of T4 by deiodination, performed by type 2 deiodinase (D2), which is already present in glial cells at fetal stage. It has been calculated that, in physiological situation, $80 \%$ of T3 in rodent brain might be produced by local deiodination of $\mathrm{T} 4$. The differential transport of T4 and T3 has an important consequence: maternal hypothyroxinemia, that is, low T4 level in maternal serum with T3 and TSH levels within normal range, is a cause of neurodevelopmental disorders [3]. Even mild maternal hypothyroxinemia was recently found to be associated with a higher risk of delay in the onset of expressive language of children [8]. This situation is much more frequent than overt hypothyroidism in geographical areas with low iodine uptake. Reporter mice have been made, in which lacZ expression is controlled by a Gal4-TR $\alpha 1$ artificial fusion protein, to visualize T3 signaling in brain [9]. These so-called FINDT3 mice revealed two interesting 
features. First T3 visibly activates transgene expression at fetal stage (embryonic day 15.5). Second T3 signaling is highly heterogeneous, and large variations of reporter gene expression are observed depending on brain areas. Midbrain and telencephalon appear to be places of high signaling. This signaling pattern in adults is well correlated with T3 distribution measured in various brain areas $[10,11]$, suggesting that local T3 concentration is the main determinant of signaling and that unknown mechanisms maintain an heterogeneous distribution of T3 in brain. A number of transporters have been identified, which might participate to the transfer of $\mathrm{TH}$ to the brain [12]. However, knockout of individual transporters does not seem to affect neurodevelopment, suggesting a cooperation between several transporters. One transporter that received considerable attention is the monocarboxylate transporter 8 , encoded by an X-linked MCT8 (SLC16A2) gene. Human mutations of MCT8 increase rather than suppress $\mathrm{TH}$ circulating levels but have dramatic consequences on neurodevelopment, therefore suggesting a predominant function of MCT8 for $\mathrm{TH}$ transport across the brain-blood barrier [13]. However, the knockout of MCT8 does not have any obvious influence on mouse brain development and the reasons for this discrepancy are unclear. Two alternative possibilities can be proposed: the first would be that human MCT8 is able to transport not only $\mathrm{TH}$ but also some unknown signaling molecule required for proper brain development. This hypothesis is consistent with the clinical observations of patients with MCT8 mutations, which display a syndrome that is apparently distinct and more severe that congenital hypothyroidism. The other possible explanation for the mild consequences of MCT8 mutation in mice could be that other transporters, for example, the OATP14, LAT1, and LAT2 transporters, are present at earlier stages in the rodent brain, and can compensate for MCT8 deficiency in this species [14-16].

Knocking-out the Dio2 gene, which encodes D2, allowed to precisely address the function of T4 deiodination during fetal brain development, but led to surprisingly mild phenotypic alterations. No major change in T3 level was observed in serum. The reduction of T3 level at postnatal day 15 (P15) was only 50\% in cerebellum and hypothalamus, and not significant in cortex $[17,18]$. T3 level was normalized in adult brain [19]. Gene expression analysis and neurobehavior testing confirmed a very mild neurodevelopmental phenotype [17]. Crossing with FINDT3 reporter mice indicated that the spatial pattern of $\mathrm{TH}$ signaling was not obviously affected throughout development (L. Quignodon unpublished data). Type 1 deiodinase (D1 encoded by Dio1) is the other enzyme able to convert T4 into T3, and is mainly expressed in liver. Surprisingly, elimination of both Dio1 and Dio2 did not aggravate the neurobehavioral phenotype. Although Dio1/Dio2 combined knockout increased T4 level, T3 level was maintained in serum [18] and adult brain [19]. Dio2 knockout was also combined to MCT8 knockout [19, $20]$. For a set of genes that are positively regulated by T3 in cortex, this combination resulted in decreased expression, in both juveniles and adults. This suggests that T3 is produced by local deiodination of T4, or directly transported by MCT8, and that blocking both pathways leads to a status close to hypothyroidism in cortex. Looking at genes that are found to be upregulated in hypothyroid cortex revealed, however, that the situation is more complex, as, for these negatively regulated genes, only Dio2 knockout had a influence on expression level. Since the molecular mechanism underlying negative regulation of gene expression by T3 is unknown, this observation is difficult to explain, but probably suggests that the entry route of $\mathrm{T} 3$ in brain is somehow an important information to define individual gene regulation status.

The third known deiodinase, type 3 deiodinase (D3, encoded by Dio3), is responsible for T3 catabolism and is expressed in several brain areas [21]. As Dio3 gene expression in brain is upregulated in case of hyperthyroidism, local T3 catabolism can act as a safety pathway to protect brain against excess of T3. Dio3 knockout mice were crossed to FINDT3 reporter mice [22]. This revealed a slow accumulation of T3 in the anterior cortex, indicating that catabolism is required to regulate T3 level in adult cortex. Dio3 knockout did not eliminate the spatial heterogeneity of T3 signaling, at early and late stages, ruling out a major function of D3 in defining the spatial distribution of T3 in brain. In adult hypothalamus, local control of $\mathrm{T} 3$ level by deiodinases appears to be used to sense and react rapidly to external signals. Local TH metabolism participate to hypothalamic response to feeding status [23], inflammation [24], seasonal change [25, 26], and TRH feedback regulation [27]. This example might prompt to reexamine the possibility that rapid metabolism could also influence local environment during development. In conclusion, T3 signaling level greatly varies in brain, depending on brain areas, cell type, and developmental stage and measuring TH levels in blood is poorly informative. Although the system generating this heterogeneity is not understood, it appears as a very robust and insensitive to genetic mutation affecting $\mathrm{TH}$ transport and metabolism.

\section{Nuclear Receptors Function in Neurodevelopment}

The THRA and THRB genes encode a number of isoforms $[28,29]$. Among these only $\operatorname{TR} \alpha 1, \operatorname{TR} \beta 1$, and $\operatorname{TR} \beta 2$ are considered as T3-dependent activators of nuclear transcription. TR $\alpha 1$ mRNA is ubiquitous in brain, both in neuronal and glial cell types whereas TR $\beta 1$ expression is more restricted with prominent expression in zones of neuroblasts proliferation such as the germinal trigone and the cortical ventricular zone. TR $\beta 2$ expression in brain is limited to the developing hippocampus and striatum [30-32]. To more precisely address THRA expression pattern, a mouse strain that expresses TR $\alpha 1$ and green fluorescent protein (Gfp) as a chimeric protein from the THRA locus has been recently created by homologous recombination [33]. Immunocytochemistry against Gfp confirmed a broad expression, but also indicates important variations in expression level. Although very reliable, this method is probably of limited sensitivity, and absence of detection should not be taken as a proof for absence of expression. For example, Gfp is detected first at embryonic day 13.5 (E13.5) whereas in situ hybridization indicates earlier expression [30]. One interesting case is the Purkinje neurons in cerebellum, in which TR $\alpha 1$ expression 
decreases overtime while TR $\beta 1$ gradually increases, suggesting a series of postnatal maturation events [34] enrolling the two receptors sequentially.

Due to the difficulty to detect endogenous proteins by Western blotting [35] or immunocytochemistry [36], THRA and THRB expression studies in brain have been limited to mRNA analysis. This is regrettable because TR $\alpha 1 \mathrm{mRNA}$ can encode several proteins, beside the canonical receptor [37]. Among these, the p43 protein is translated from a downstream AUG codon, providing a $43 \mathrm{kDa}$ protein lacking the $\mathrm{N}$-terminus of the TR $\alpha 1$ canonical receptor. This p43 isoform has been proposed to be targeted to mitochondria and to regulate mitochondrial genome transcription, providing a possible complement to the well-known nuclear activation of genes encoding mitochondrial enzymes [38] which is relevant to neurodevelopment $[39,40]$. The involvement in neurodevelopment of $\mathrm{p} 43$, as well as other so-called nongenomic pathways for T3 action [41] would merit specific investigation. T3 is also a precursor of thyronamines, which are present in brain, and activate a different class of membranes receptors also expressed in brain [42], but which neurodevelopmental function has not yet been evaluated.

Initial studies of THRA and THRB knockouts were surprising. THRA knockout has no visible consequence on cerebellum, a posterior brain structure which postnatal development is highly sensitive to $\mathrm{TH}$ deficiency, and is the most classical model to study congenital hypothyroidism in rodents [43]. It induces increased anxiety in adults, which probably involves hippocampus function, but does not necessarily reflect a developmental defect. THRB knockout affects hearing [44] and vision [45] but not the central nervous system development. No developmental defect has been reported after combining THRA and THRB knockout $[46,47]$. The inability of THRA/THRB knockout to phenocopy congenital hypothyroidism was explained by depleting THRA knockout newborns of T3 by potassium perchlorate and 1-methyl-2-mercaptoimidazole treatment. In the cerebellum of these mice, the persistence of the external granular layer, a typical sign of congenital hypothyroidism normally induced by $\mathrm{T} 3$ depletion, was absent [48]. This strongly suggests that the manifestations of congenital hypothyroidism in brain are mainly due to the presence of unliganded TR $\alpha 1$, which is bound to DNA and represses transcription. Knockin mutations in THRA have been produced to introduce point mutations in the TR $\alpha 1$ reading frame and compromise its ability to transactivate upon T3 binding, without impairing its ability to repress transcription. As expected, such mutations, unlike the THRA knockout, lead to a cerebellum phenotype resembling congenital hypothyroidism $[49,50]$, and these defects are not limited to cerebellum $[51,52]$. Whether TR $\alpha 1$ is the only active $\mathrm{T} 3$ receptor during cerebellum development remains unclear. One THRB knockin mutation also produces a cerebellum phenotype resembling hypothyroidism, with some important differences, perhaps due to the associated increase in circulating $\mathrm{TH}$ levels $[53,54]$. When given to hypothyroid pups, TR $\beta$ selective ligands seem to have an effect limited to Purkinje neurons $[48,55]$. However, the action of $\mathrm{T} 3$ on in vitro Purkinje cells dendritogenesis appears to be depending on TR $\alpha 1$ rather that TR $\beta 1$ [56]. Finally, many human germline mutations have been reported in the human THRB, but not THRA, gene, responsible for a syndrome of resistance to TH [57]. Although these mutations can be a cause of IQ deficit, they do not have major neurological consequences [58].

\section{TH and Neurodevelopment: How Much Is Cell Autonomous?}

Most detailed studies are focused on cerebellum postnatal development in rodents, where each cell type is sensitive in some respect to $\mathrm{TH}$ deficiency: the inward migration of the granular cell precursors (GCPs) present in the granular layer cells (EGL) is inhibited, the development of the dendritic arborization of Purkinje neurons is impaired, and the maturation of the GABAergic interneurons is delayed [59]. The proliferation and differentiation of glial cells, including astrocytes [60,61], oligodendrocyte precursors [62], and microglia [63] are affected. The morphology of Bergmann glia, a specific type of radial glia found only in cerebellum, is abnormal [64]. The diversity of these effects raises several possibilities for the mode of action of T3. The first would be that the repertoire of T3 target genes is completely different in different cell types, and that genetic programs governing cell migration, cell proliferation, and cytological maturation are regulated in a cell-specific manner. In this case, the chromatin status in a given cell type would exert a predominant influence to define the repertoire of TR target genes. The alternative would be that $\mathrm{T} 3$ exerts similar effects in different cell types, controlling a shared repertoire of TR target genes, but that this cell-autonomous response would represent only a small fraction of the observed effects of T3. TH deficiency is known to affect the level of several neurotrophic and growth factors in brain, which are required for proper development $[65,66]$. Cell culture can be used to distinguish between these two possibilities, and to address the cell autonomous response of purified or enriched cell populations to T3, isolated from their natural environment. Purkinje cells [56], oligodendrocyte precursors [67], and astrocytes [68] were all shown to respond to in vitro stimulation by T3. By contrast, impaired migration of GCPs, which is a main sign of congenital hypothyroidism, is possibly an indirect effect for several reasons. First, this cell type does not express TR $\alpha 1$ at a high level [33]. Second, microarray analysis, performed on primary cultures of GCPs, identified very limited changes in gene expression after T3 exposure, and failed to establish a direct link between T3 and known mechanism of neuronal migration [69]. Third, according to in situ hybridization, GCPs do not express THRB, but their migration is affected by the TR $\beta^{\triangle 337 T}$ mutation [54]. Finally, GCPs do not produce the T3-regulated neurotrophic factors (neurotrophin 3, insulin-like growth factor-1, Sonic hedgehog, and brain-derived neurotrophic factor) but need these neurotrophic factors for their proliferation, inward migration, and differentiation [70-72]. As Purkinje cells are the main source of Sonic hedgehog and insulin-like growth factor-1, they probably play a central role in a local network of cellular interactions. However, if this local effect 
is plausible, a more indirect, systemic, influence of T3 cannot be ruled out. In that respect, it is remarkable that a metabolic disease, which is clearly restricted to the liver, has been found to impact GCPs inward migration [73]. All these observations suggest that GCPs migration, which is required to give rise to more than $90 \%$ of the cerebellum neurons, does not result from a cell autonomous action of T3. A direct genetic demonstration of this hypothesis would be possible using the CRE/loxP technology, for which THRA [50] and THRB [44] alleles are available.

\section{T3 Target Genes}

It is striking that genome-wide analysis performed by a number of groups over the years, using a variety of protocols, identified only few direct T3 targets in neural cell types, defined as genes for which transcription is under the direct control of $\operatorname{TR} \alpha 1$ or $\mathrm{TR} \beta 1$ bound to neighboring regulatory sequences. Microarray analysis showed that in vivo T3 treatment has a very limited effect on transcriptome of whole cerebellum [74-76], or fetal cortex [77], compared to adult striatum [78] or other tissues [79]. Comparison between these studies also suggests that T3 response is very different in different brain areas and at different developmental stages [80]. The effect of graded degrees of TH deficiency, induced by propyl-thio-uracyl, on gene expression has been studied in postnatal hippocampus and cortex. Interestingly, transcriptome is affected in a dosedependent manner, specific gene clusters being sensitive to only mild hypothyroidism [81]. Whereas many putative T3 target genes have been listed in these broad surveys, most changes are not rapidly reversed when $\mathrm{T} 3$ is given to hypothyroid animals, and might reflect changes in the cell composition of the considered area, or in the differentiation status or the cell types. This is probably the case, for example, for genes expressed in mature oligodendrocytes, as differentiation of this cell type is known to be regulated by T3. The actual demonstration of direct regulation by $\mathrm{T} 3 / \mathrm{TR}$ requires deeper investigations, which have been done in only few cases. First, transcriptional regulation in a primary culture system, where environmental parameters can be controlled, can be used to reinforce the hypothesis for a direct regulation. Second, transient expression assays can be used to test the ability of gene promoter regions to confer T3 responsiveness to reporter plasmid constructs. However, this approach is often of little physiological relevance and is hardly feasible in appropriate cell types. Finally, chromatin immunoprecipitation, now considered as a gold standard, can demonstrate actual binding by TR $\alpha 1$ or $\operatorname{TR} \beta 1$ on putative response elements in their natural genomic environment. This method appears to be much more reliable than in vitro protein/DNA interaction assays, which do not account for the complexity of the cellular chromatin context but remains technically challenging for several reasons. First, data obtained in other systems suggest that the distance between TR binding sites and transcription start site can be very large, making it difficult to make a selection among many putative response elements, and to ensure that TR occupancy is responsible for the observed regulation. Second, it is hardly feasible to perform such studies on purified cerebellar cell populations. Preparing chromatin from whole cerebellum [82] mainly addresses chromatin occupancy in granular neurons, which represent a large majority of the cerebellum cells. One attempt has been made to identify new T3 target genes by the so-called chipon-chip high-throughput analysis [75].

Ironically, Hairless $(\mathrm{Hr})$, encoding a transcriptional corepressor of several nuclear receptors, continues to be the bestcharacterized T3 target gene in neurons, fifteen years after its identification as a T3 target gene in rat postnatal cerebellum [83]. Its expression is rapidly induced in a number of neuronal cell types, and TR occupancy in the promoter region has been confirmed by chromatin immunoprecipitation [69]. Among other likely TR $\alpha 1 / \mathrm{TR} \beta 1$ direct target genes in neurodevelopment, are genes encoding a Krüppel-like transcription factor (Klf9) [84], a poorly studied synaptotagminrelated gene ( $\operatorname{srg} 1)$ [85], A kinase (PRKA) anchor protein 1 (Akap1) [69], neurogranin (RC3/Nrgn) [86], and, in the fetal cortex, Ca2+/calmodulin-dependent protein kinase IV (Camk4) [77]. The paucity in well-characterized T3 target genes in brain mainly stems from the high cellular heterogeneity of neural tissues, and the lack of suitable in vitro systems. It remains a bottleneck for the analysis of the mechanisms underlying the neurodevelopmental function of T3.

\section{A New Class of Neurotoxic Thyroid Hormone Disruptors?}

The above considerations have significant consequences for a matter of growing public concern: a number of chemicals found at low concentration in the water and food are suspected to exert a chronic toxicity by interfering with T3 signaling, and might thus be considered as putatively neurotoxic [87]. The main suspected compounds are Bisphenol A [88] flame retardants (tetra-bromo-bisphenol A [89], polybrominated diphenyl ethers [90]) and the persistent polychlorobiphenyls (PCBs) [91]. Acute exposure of rats to these compounds can lower or raise the circulating level of TH. Xenopus tadpole metamorphosis, which is fully dependent on $\mathrm{TH}$, provides a basis for an in vivo assay recognized by the Organisation for Cooperation and Development (OECD) to define TH disruptors. The recently developed assay, based on transgenic xenopus tadpoles is a promising alternative, as it is rapid, and might better address TR $\alpha 1$ function [92]. In some cases, transactivation assays performed in transfected cell lines, or primary cultures of neural cells, confirm a possible direct influence of chemicals on T3 signaling [93]. Although some compounds, like coplanar PCBs, display some structural similarities with T3, they do not seem to fit into the T3 binding pocket and are thus unlikely to act as high-affinity TR $\alpha 1 / \mathrm{TR} \beta 1$ ligands. Recent data suggests, however, noncompetitive binding to $\mathrm{TR}$, preventing interactions with DNA [94]. In most cases, a systemic influence on T3 metabolism and transport can account for most of the observed in vivo toxicity after acute exposure. Few experiments address the possibility that $\mathrm{TH}$ disruptors can interfere with the neurodevelopmental function of T3, although significant effects on gene expression 
in brain have been reported after exposure to a high dose of PCBs [95, 96] or bisphenol A [97]. One could argue that the powerful compensatory mechanisms, revealed by the knockout of genes encoding transporters and deiodinases, would be sufficient to maintain a stable level of T3 in brain in most cases. Chronic exposure to a low dose of chemicals, acting on T3 transport and metabolism, would thus be unlikely to have neurotoxic consequences, unless other signaling pathways are involved. In fact, T3 level in brain is maintained in case of mild TH deficiency [98], a condition which already requires exposure to high doses of TH disruptors. By contrast, the results of THRA knockin mutations suggest that exposure to any chemical that would act as a TR $\alpha 1$ antagonist would be expected to significantly impair neurodevelopment. If such a hypothetical chemical was TR $\alpha 1$ selective, it would not change the circulating level of $\mathrm{TH}$ in serum, as this regulation is mainly exerted by TR $\beta 1$ and TR $\beta 2$. Therefore TR $\alpha 1$ antagonists would not be necessarily recognized by most in vivo tests. Defining the neural cell types that respond in a cell autonomous manner to T3 during neurodevelopment, and then identifying direct TR $\alpha 1$ target genes in these cells, appears therefore as a prerequisite to the definition of relevant endpoints for future toxicity assay development.

\section{Conclusion}

Recent advances in our understanding of the neurodevelopmental function of T3 heavily rely on mouse genetics. A complex landscape in which T3 probably exerts a number of different functions in different cell types has been uncovered. Coordinating the network of interactions, mediated by direct contacts and exchanges of diffusible factors, T3 synchronizes neuronal and glial cells differentiation to ensure the onset of functional neuronal structures. Whereas the transport and metabolism of T3 is a robust system, which enables to maintain T3 level within physiological range in many situations, signal transduction in the developing brain mainly relies on the TR $\alpha 1$ isoform. Single amino-acid substitutions can have dramatic consequences on neurodevelopment and phenocopy congenital hypothyroidism. This is probably the reason why no THRA germline mutation has been reported, and why single nucleotide polymorphism in the human locus are only found in noncoding sequences.

\section{References}

[1] P. Laurberg, "Thyroid function: thyroid hormones, iodine and the brainan important concern," Nature Reviews Endocrinology, vol. 5, no. 9, pp. 475-476, 2009.

[2] G. M. De Escobar, M. J. Obregón, and F. E. Del Rey, "Iodine deficiency and brain development in the first half of pregnancy," Public Health Nutrition, vol. 10, no. 12, pp. 15541570, 2007.

[3] P. Berbel, M. J. Obregón, J. Bernal, F. E. D. Rey, and G. M. D. Escobar, "Iodine supplementation during pregnancy: a public health challenge," Trends in Endocrinology and Metabolism, vol. 18, no. 9, pp. 338-343, 2007.

[4] D. V. Becker, L. E. Braverman, F. Delange et al., "Iodine supplementation for pregnancy and lactation-United States and Canada: recommendations of the American Thyroid Association," Thyroid, vol. 16, no. 10, pp. 949-951, 2006.

[5] S. Y. Chan, E. Vasilopoulou, and M. D. Kilby, "The role of the placenta in thyroid hormone delivery to the fetus," Nature Clinical Practice Endocrinology and Metabolism, vol. 5, no. 1, pp. 45-54, 2009.

[6] R. Calvo, M. J. Obregon, C. Ruiz de Ona, F. Escobar del Rey, and G. Morreale de Escobar, "Congenital hypothyroidism, as studied in rats. Crucial role of maternal thyroxine but not of $3,5,3$ '-triiodothyronine in the protection of the fetal brain," Journal of Clinical Investigation, vol. 86, no. 3, pp. 889-899, 1990.

[7] C. Grijota-Martinez, D. Diez, G. Morreale de Escobar, J. Bernal, and B. Morte, "Lack of action of exogenously administered T3 on the fetal rat brain despite expression of the monocarboxylate transporter 8," Endocrinology, vol. 152, pp. 1713-1721, 2011.

[8] J. Henrichs, J. J. Bongers-Schokking, J. J. Schenk et al., "Maternal thyroid function during early pregnancy and cognitive functioning in early childhood: the generation $\mathrm{R}$ study," Journal of Clinical Endocrinology and Metabolism, vol. 95, no. 9, pp. 4227-4234, 2010.

[9] L. Quignodon, C. Legrand, N. Allioli et al., "Thyroid hormone signaling is highly heterogeneous during pre- and postnatal brain development," Journal of Molecular Endocrinology, vol. 33, no. 2, pp. 467-476, 2004.

[10] J. A. Palha, J. Nissanov, R. Fernandes et al., "Thyroid hormone distribution in the mouse brain: the role of transthyretin," Neuroscience, vol. 113, no. 4, pp. 837-847, 2002.

[11] G. Pinna, O. Brödel, T. Visser et al., "Concentrations of seven iodothyronine metabolites in brain regions and the liver of the adult rat," Endocrinology, vol. 143, no. 5, pp. 1789-1800, 2002.

[12] W. E. Visser, E. C. H. Friesema, and T. J. Visser, "Minireview: thyroid hormone transporters: the knowns and the unknowns," Molecular Endocrinology, vol. 25, no. 1, pp. 1-14, 2011.

[13] E. C. H. Friesema, W. E. Visser, and T. J. Visser, "Genetics and phenomics of thyroid hormone transport by MCT8," Molecular and Cellular Endocrinology, vol. 322, no. 1-2, pp. 107-113, 2010.

[14] E. K. Wirth, S. Roth, C. Blechschmidt et al., "Neuronal 3',3,5triiodothyronine $(\mathrm{T})$ uptake and behavioral phenotype of mice deficient in Mct8, the neuronal T3 transporter mutated in Allan-Herndon-Dudley syndrome," Journal of Neuroscience, vol. 29, no. 30, pp. 9439-9449, 2009.

[15] L. M. Roberts, K. Woodford, M. Zhou et al., "Expression of the thyroid hormone transporters monocarboxylate transporter-8 (SLC16A2) and organic ion transporter-14 (SLCO1C1) at the blood-brain barrier," Endocrinology, vol. 149, no. 12, pp. 62516261, 2008.

[16] D. Braun, A. Kinne, A. U. Brauer et al., "Developmental and cell type-specific expression of thyroid hormone transporters in the mouse brain and in primary brain cells," GLIA, vol. 59, no. 3, pp. 463-471, 2011.

[17] V. A. Galton, E. T. Wood, E. A. St Germain et al., "Thyroid hormone homeostasis and action in the type 2 deiodinasedeficient rodent brain during development," Endocrinology, vol. 148, no. 7, pp. 3080-3088, 2007.

[18] V. A. Galton, M. J. Schneider, A. S. Clark, and D. L. ST. Germain, "Life without thyroxine to 3,5,3'-triiodothyronine conversion: studies in mice devoid of the $5^{\prime}$-deiodinases," Endocrinology, vol. 150, no. 6, pp. 2957-2963, 2009. 
[19] X.-H. Liao, C. Di Cosmo, A. M. Dumitrescu et al., "Distinct roles of deiodinases on the phenotype of Mct8 defect: a comparison of eight different mouse genotypes," Endocrinology, vol. 152, no. 3, pp. 1180-1191, 2011.

[20] B. Morte, A. Ceballos, D. Diez et al., "Thyroid hormoneregulated mouse cerebral cortex genes are differentially dependent on the source of the hormone: a study in monocarboxylate transporter-8- and deiodinase-2-deficient mice," Endocrinology, vol. 151, no. 5, pp. 2381-2387, 2010.

[21] D. L. St Germain, V. A. Galton, and A. Hernandez, "Miniereview: defining the roles of the lodothyronine deiodinases: current concepts and challenges," Endocrinology, vol. 150, no. 3, pp. 1097-1107, 2009.

[22] A. Hernandez, L. Quignodon, M. E. Martinez, F. Flamant, and D. L. St. Germain, “Type 3 deiodinase deficiency causes spatial and temporal alterations in brain T3 signaling that are dissociated from serum thyroid hormone levels," Endocrinology, vol. 151, no. 11, pp. 5550-5558, 2010.

[23] A. Coppola, Z. W. Liu, Z. B. Andrews et al., "A central thermogenic-like mechanism in feeding regulation: an interplay between arcuate nucleus T3 and UCP2," Cell Metabolism, vol. 5, no. 1, pp. 21-33, 2007.

[24] J. Kwakkel, O. Chassande, H. C. Van Beeren, E. Fliers, W. M. Wiersinga, and A. Boelen, "Thyroid hormone receptor $\alpha$ modulates lipopolysaccharide-induced changes in peripheral thyroid hormone metabolism," Endocrinology, vol. 151, no. 4, pp. 1959-1969, 2010.

[25] T. Watanabe, T. Yamamura, M. Watanabe et al., "Hypothalamic expression of thyroid hormone-activating and inactivating enzyme genes in relation to photorefractoriness in birds and mammals," American Journal of Physiology, vol. 292, no. 1, pp. R568-R572, 2007.

[26] N. Nakao, H. Ono, T. Yamamura et al., "Thyrotrophin in the pars tuberalis triggers photoperiodic response," Nature, vol. 452, no. 7185, pp. 317-322, 2008.

[27] M. I. Chiamolera and F. E. Wondisford, "Minireview: thyrotropin-releasing hormone and the thyroid hormone feedback mechanism," Endocrinology, vol. 150, no. 3, pp. 1091-1096, 2009.

[28] F. Flamant and J. Samarut, "Thyroid hormone receptors: lessons from knockout and knock-in mutant mice," Trends in Endocrinology and Metabolism, vol. 14, no. 2, pp. 85-90, 2003.

[29] F. Flamant, J. D. Baxter, D. Forrest et al., "International union of pharmacology. 59. The pharmacology and classification of the nuclear receptor superfamily: thyroid hormone receptors," Pharmacological Reviews, vol. 58, no. 4, pp. 705-711, 2006.

[30] D. J. Bradley, H. C. Towle, and W. S. Young III, "Spatial and temporal expression of $\alpha$ - and $\beta$-thyroid hormone receptor mRNAs, including the $\beta 2$-subtype, in the developing mammalian nervous system," Journal of Neuroscience, vol. 12, no. 6, pp. 2288-2302, 1992.

[31] D. J. Bradley, W. S. Young, and C. Weinberger, "Differential expression of $\alpha$ and $\beta$ thyroid hormone receptor genes in rat brain and pituitary," Proceedings of the National Academy of Sciences of the United States of America, vol. 86, no. 18, pp. 7250-7254, 1989.

[32] B. Mellstrom, J. R. Naranjo, A. Santos et al., "Independent expression of the $\alpha$ and $\beta$ c-erbA genes in developing rat brain," Molecular Endocrinology, vol. 5, no. 9, pp. 1339-1350, 1991.
[33] K. Wallis, S. Dudazy, M. Van Hogerlinden, K. Nordström, J. Mittag, and B. Vennström, "The thyroid hormone receptor $\alpha 1$ protein is expressed in embryonic postmitotic neurons and persists in most adult neurons," Molecular Endocrinology, vol. 24, no. 10, pp. 1904-1916, 2010.

[34] F. Boukhtouche, B. Brugg, R. Wehrlé et al., "Induction of early Purkinje cell dendritic differentiation by thyroid hormone requires ROR $\alpha$," Neural Development, vol. 5, no. 1, article 18, 2010.

[35] M. Knipper, C. Bandtlow, L. Gestwa et al., "Thyroid hormone affects Schwann cell and oligodendrocyte gene expression at the glial transition zone of the VIII(th) nerve prior to cochlea function," Development, vol. 125, no. 18, pp. 3709-3718, 1998.

[36] M. Plateroti, K. Gauthier, C. Domon-Dell, J.-N. Freund, J. Samarut, and O. Chassande, "Functional interference between thyroid hormone receptor $\alpha(\mathrm{TR} \alpha)$ and natural truncated TR $\Delta \alpha$ isoforms in the control of intestine development," Molecular and Cellular Biology, vol. 21, no. 14, pp. 4761-4772, 2001.

[37] J. Bigler, W. Hokanson, and R. N. Eisenman, "Thyroid hormone receptor transcriptional activity is potentially autoregulated by truncated forms of the receptor," Molecular and Cellular Biology, vol. 12, no. 5, pp. 2406-2417, 1992.

[38] C. Wrutniak-Cabello, F. Casas, and G. Cabello, "Thyroid hormone action in mitochondria," Journal of Molecular Endocrinology, vol. 26, no. 1, pp. 67-77, 2001.

[39] B. Martinez, T. B. Rodrigues, E. Gine, J. P. Kaninda, A. PerezCastillo, and A. Santos, "Hypothyroidism decreases the biogenesis in free mitochondria and neuronal oxygen consumption in the cerebral cortex of developing rats," Endocrinology, vol. 150, no. 8, pp. 3953-3959, 2009.

[40] R. A. Sinha, A. Pathak, V. Mohan et al., "Evidence of a bigenomic regulation of mitochondrial gene expression by thyroid hormone during rat brain development," Biochemical and Biophysical Research Communications, vol. 397, no. 3, pp. 548-552, 2010.

[41] S. Y. Cheng, J. L. Leonard, and P. J. Davis, "Molecular aspects of thyroid hormone actions," Endocrine Reviews, vol. 31, no. 2, pp. 139-170, 2010.

[42] S. Piehl, C. S. Hoefig, T. S. Scanlan, and J. Köhrle, "Thyronamines-past, present, and future," Endocrine Reviews, vol. 32, no. 1, pp. 64-80, 2011.

[43] J. L. Nicholson and J. Altman, "The effects of early hypoand hyperthyroidism on the development of the rat cerebellar cortex. II. Synaptogenesis in the molecular layer," Brain Research, vol. 44, no. 1, pp. 25-36, 1972.

[44] H. Winter, L. Rüttiger, M. Müller et al., "Deafness in TR $\beta$ mutants is caused by malformation of the tectorial membrane," Journal of Neuroscience, vol. 29, no. 8, pp. 2581-2587, 2009.

[45] A. Swaroop, D. Kim, and D. Forrest, "Transcriptional regulation of photoreceptor development and homeostasis in the mammalian retina," Nature Reviews Neuroscience, vol. 11, no. 8, pp. 563-576, 2010.

[46] S. Göthe, Z. Wang, L. Ng et al., "Mice devoid of all known thyroid are viable hormone receptors but exhibit disorders of the pituitary-thyroid axis, growth, and bone maturation," Genes and Development, vol. 13, no. 10, pp. 1329-1341, 1999.

[47] K. Gauthier, O. Chassande, M. Plateroti et al., "Different functions for the thyroid hormone receptors $\operatorname{TR} \alpha$ and $\operatorname{TR} \beta$ in the control of thyroid hormone production and post-natal development," EMBO Journal, vol. 18, no. 3, pp. 623-631, 1999. 
[48] B. Morte, J. Manzano, T. Scanlan, B. Vennström, and J. Bernal, "Deletion of the thyroid hormone receptor $\alpha 1$ prevents the structural alterations of the cerebellum induced by hypothyroidism," Proceedings of the National Academy of Sciences of the United States of America, vol. 99, no. 6, pp. 3985-3989, 2002.

[49] C. Venero, A. Guadaño-Ferraz, A. I. Herrero et al., "Anxiety, memory impairment, and locomotor dysfunction caused by a mutant thyroid hormone receptor $\alpha 1$ can be ameliorated by T3 treatment," Genes and Development, vol. 19, no. 18, pp. 2152-2163, 2005.

[50] L. Quignodon, S. Vincent, H. Winter, J. Samarut, and F. Flamant, "A point mutation in the activation function 2 domain of thyroid hormone receptor $\alpha 1$ expressed after CRE-mediated recombination partially recapitulates hypothyroidism," Molecular Endocrinology, vol. 21, no. 10, pp. 23502360, 2007.

[51] S. Hadjab-Lallemend, K. Wallis, M. van Hogerlinden et al., "A mutant thyroid hormone receptor alphal alters hippocampal circuitry and reduces seizure susceptibility in mice," $\mathrm{Neu}$ ropharmacology, vol. 58, no. 7, pp. 1130-1139, 2010.

[52] M. Pilhatsch, C. Winter, K. Nordström, B. Vennström, M. Bauer, and G. Juckel, "Increased depressive behaviour in mice harboring the mutant thyroid hormone receptor alpha 1," Behavioural Brain Research, vol. 214, pp. 187-192, 2010.

[53] K. Hashimoto, F. H. Curty, P. P. Borges et al., "An unliganded thyroid hormone receptor causes severe neurological dysfunction," Proceedings of the National Academy of Sciences of the United States of America, vol. 98, no. 7, pp. 3998-4003, 2001.

[54] A. C. Portella, F. Carvalho, L. Faustino, F. E. Wondisford, T. M. Ortiga-Carvalho, and F. C. A. Gomes, "Thyroid hormone receptor $\beta$ mutation causes severe impairment of cerebellar development," Molecular and Cellular Neuroscience, vol. 44, no. 1, pp. 68-77, 2010.

[55] C. Grijota-Martínez, E. Samarut, T. S. Scanlan, B. Morte, and J. Bernal, "In vivo activity of the thyroid hormone receptor $\beta$ and $\alpha$-selective agonists GC-24 and CO23 on rat liver, heart, and brain," Endocrinology, vol. 152, no. 3, pp. 1136-1142, 2011.

[56] H. Heuer and C. A. Mason, "Thyroid hormone induces cerebellar purkinje cell dendritic development via the thyroid hormone receptor $\alpha 1$," Journal of Neuroscience, vol. 23, no. 33, pp. 10604-10612, 2003.

[57] R. E. Weiss and S. Refetoff, "Resistance to thyroid hormone," Reviews in Endocrine and Metabolic Disorders, vol. 1, no. 1-2, pp. 97-108, 2000.

[58] R. E. Weiss, M. A. Stein, S. C. Duck et al., "Low intelligence but not attention deficit hyperactivity disorder is associated with resistance to thyroid hormone caused by mutation $\mathrm{R} 316 \mathrm{H}$ in the thyroid hormone receptor $\beta$ gene," Journal of Clinical Endocrinology and Metabolism, vol. 78, no. 6, pp. 1525-1528, 1994.

[59] J. Manzano, M. Cuadrado, B. Morte, and J. Bernal, "Influence of thyroid hormone and thyroid hormone receptors in the generation of cerebellar $\gamma$-aminobutyric acid-ergic interneurons from precursor cells," Endocrinology, vol. 148, no. 12, pp. 5746-5751, 2007.

[60] C. B. N. Mendes-de-Aguiar, R. Alchini, H. Decker, M. AlvarezSilva, C. I. Tasca, and A. G. Trentin, "Thyroid hormone increases astrocytic glutamate uptake and protects astrocytes and neurons against glutamate toxicity," Journal of Neuroscience Research, vol. 86, no. 14, pp. 3117-3125, 2008.

[61] A. G. Trentin, "Thyroid hormone and astrocyte morphogenesis," Journal of Endocrinology, vol. 189, no. 2, pp. 189-197, 2006.
[62] B. Durand and M. Raff, "A cell-intrinsic timer that operates during oligodendrocyte development," BioEssays, vol. 22, no. 1, pp. 64-71, 2000.

[63] F. R. S. Lima, A. Gervais, C. Colin, M. Izembart, V. M. Neto, and M. Mallat, "Regulation of microglial development: a novel role for thyroid hormone," Journal of Neuroscience, vol. 21, no. 6, pp. 2028-2038, 2001.

[64] J. Manzano, J. Bernal, and B. Morte, "Influence of thyroid hormones on maturation of rat cerebellar astrocytes," International Journal of Developmental Neuroscience, vol. 25, no. 3, pp. 171-179, 2007.

[65] T. Giordano, J. B. Pan, D. Casuto, S. Watanabe, and S. P. Arneric, "Thyroid hormone regulation of NGF, NT-3 and BDNF RNA in the adult rat brain," Molecular Brain Research, vol. 16, no. 3-4, pp. 239-245, 1992.

[66] I. Neveu and E. Arenas, "Neurotrophins promote the survival and development of neurons in the cerebellum of hypothyroid rats in vivo," Journal of Cell Biology, vol. 133, no. 3, pp. 631646, 1996.

[67] B. A. Barres, M. A. Lazar, and M. C. Raff, "A novel role for thyroid hormone, glucocorticoids and retinoic acid in timing oligodendrocyte development," Development, vol. 120, no. 5, pp. 1097-1108, 1994.

[68] A. G. Trentin, F. C. A. Gomes, F. R. S. Lima, and V. M. Neto, "Thyroid hormone acting on astrocytes in culture," In Vitro Cellular and Developmental Biology, vol. 34, no. 4, pp. 280282, 1998.

[69] L. Quignodon, C. Grijota-Martinez, E. Compe et al., "A combined approach identifies a limited number of new thyroid hormone target genes in post-natal mouse cerebellum," Journal of Molecular Endocrinology, vol. 39, no. 1-2, pp. 17-28, 2007.

[70] M. L. Doughty, A. Lohof, A. Campana, N. Delhaye-Bouchaud, and J. Mariani, "Neurotrophin-3 promotes cerebellar granule cell exit from the EGL," European Journal of Neuroscience, vol. 10, no. 9, pp. 3007-3011, 1998.

[71] S. Subramaniam, N. Shahani, J. Strelau et al., "Insulin-like growth factor 1 inhibits extracellular signal-regulated kinase to promote neuronal survival via the phosphatidylinositol 3-kinase/protein kinase A/c-Raf pathway," Journal of Neuroscience, vol. 25, no. 11, pp. 2838-2852, 2005.

[72] C. Fernandez, V. M. Tatard, N. Bertrand, and N. Dahmane, "Differential modulation of sonic-hedgehog-induced cerebellar granule cell precursor proliferation by the IGF signaling network," Developmental Neuroscience, vol. 32, no. 1, pp. 5970, 2010.

[73] O. Krysko, L. Hulshagen, A. Janssen et al., "Neocortical and cerebellar developmental abnormalities in conditions of selective elimination of peroxisomes from brain or from liver," Journal of Neuroscience Research, vol. 85, no. 1, pp. 58-72, 2007.

[74] A. L. Poguet, C. Legrand, X. Feng et al., "Microarray analysis of knockout mice identifies cyclin D2 as a possible mediator for the action of thyroid hormone during the postnatal development of the cerebellum," Developmental Biology, vol. 254, no. 2, pp. 188-199, 2003.

[75] H. Dong, C. L. Yauk, A. Rowan-Carroll et al., "Identification of thyroid hormone receptor binding sites and target genes using ChIP-on-chip in developing mouse cerebellum," PLoS ONE, vol. 4, no. 2, article e4610, 2009.

[76] M. Takahashi, T. Negishi, and T. Tashiro, "Identification of genes mediating thyroid hormone action in the developing mouse cerebellum," Journal of Neurochemistry, vol. 104, no. 3, pp. 640-652, 2008. 
[77] B. Morte, D. Díez, E. Ausó et al., "Thyroid hormone regulation of gene expression in the developing rat fetal cerebral cortex: prominent role of the $\mathrm{Ca} / \mathrm{calmodulin}$-dependent protein kinase IV pathway," Endocrinology, vol. 151, no. 2, pp. 810 $820,2010$.

[78] D. Diez, C. Grijota-Martinez, P. Agretti et al., "Thyroid hormone action in the adult brain: gene expression profiling of the effects of single and multiple doses of triiodo-L-thyronine in the rat striatum," Endocrinology, vol. 149, no. 8, pp. 39894000, 2008.

[79] P. M. Yen, "Physiological and molecular basis of thyroid hormone action," Physiological Reviews, vol. 81, no. 3, pp. 1097-1142, 2001.

[80] K. Kobayashi, H. Akune, K. Sumida, K. Saito, T. Yoshioka, and R. Tsuji, "Perinatal exposure to PTU decreases expression of Arc, Homer 1, Egr 1 and Kcna 1 in the rat cerebral cortex and hippocampus," Brain Research, vol. 1264, pp. 24-32, 2009.

[81] J. E. Royland, J. S. Parker, and M. E. Gilbert, "A genomic analysis of subclinical hypothyroidism in hippocampus and neocortex of the developing rat brain," Journal of Neuroendocrinology, vol. 20, no. 12, pp. 1319-1338, 2008.

[82] E. Compe, M. Malerba, L. Soler, J. Marescaux, E. Borrelli, and J. M. Egly, "Neurological defects in trichothiodystrophy reveal a coactivator function of TFIIH," Nature Neuroscience, vol. 10, no. 11, pp. 1414-1422, 2007.

[83] C. C. Thompson, "Thyroid hormone-responsive genes in developing cerebellum include a novel synaptotagmin and a hairless homolog," Journal of Neuroscience, vol. 16, no. 24, pp. 7832-7840, 1996.

[84] R. J. Denver and K. E. Williamson, "Identification of a thyroid hormone response element in the mouse Krüppel-like factor 9 gene to explain its postnatal expression in the brain," Endocrinology, vol. 150, no. 8, pp. 3935-3943, 2009.

[85] G. B. Potter, F. Facchinetti, G. M. J. Beaudoin, and C. C. Thompson, "Neuronal expression of synaptotagmin-related gene 1 is regulated by thyroid hormone during cerebellar development," Journal of Neuroscience, vol. 21, no. 12, pp. 4373-4380, 2001.

[86] B. Morte, C. Martínez De Arrieta, J. Manzano, A. Coloma, and J. Bernal, "Identification of a cis-acting element that interferes with thyroid hormone induction of the neurogranin (NRGN) gene," FEBS Letters, vol. 464, no. 3, pp. 179-183, 1999.

[87] R. T. Zoeller, "Environmental chemicals as thyroid hormone analogues: new studies indicate that thyroid hormone receptors are targets of industrial chemicals?" Molecular and Cellular Endocrinology, vol. 242, no. 1-2, pp. 10-15, 2005.

[88] S. Kitamura, T. Suzuki, S. Sanoh et al., "Comparative study of the endocrine-disrupting activity of bisphenol A and 19 related compounds," Toxicological Sciences, vol. 84, no. 2, pp. 249-259, 2005.

[89] L. T. M. Van der Ven, T. Van de Kuil, A. Verhoef et al., "Endocrine effects of tetrabromobisphenol-A (TBBPA) in Wistar rats as tested in a one-generation reproduction study and a subacute toxicity study," Toxicology, vol. 245 , no. 1-2, pp. 76-89, 2008.

[90] J. Chevrier, K. G. Harley, A. Bradman, M. Gharbi, A. Sjödin, and B. Eskenazi, "Polybrominated diphenyl ether (PBDE) flame retardants and thyroid hormone during pregnancy," Environmental Health Perspectives, vol. 118, no. 10, pp. 1444-1449, 2010.
[91] R. T. Zoeller, "Polychlorinated biphenyls as disruptors of thyroid hormone action," in PCBs: Recent Advances in Environmental Toxicology and Health Effects, L. W. Robertson and L. G. Hansen, Eds., pp. 265-269, PCBs University Press of Kentucky, 2001.

[92] J. B. Fini, S. Le Mevel, N. Turque et al., "An in vivo multiwellbased fluorescent screen for monitoring vertebrate thyroid hormone disruption," Environmental Science and Technology, vol. 41, no. 16, pp. 5908-5914, 2007.

[93] K. Ibhazehiebo, T. Iwasaki, J. Kimura-Kuroda, W. Miyazaki, N. Shimokawa, and N. Koibuchi, "Disruption of thyroid hormone receptor-mediated transcription and thyroid hormone-induced purkinje cell dendrite arborization by polybrominated diphenylethers," Environmental Health Perspectives, vol. 119, no. 2, pp. 168-175, 2011.

[94] W. Miyazaki, T. Iwasaki, A. Takeshita, C. Tohyama, and N. Koibuchi, "Identification of the functional domain of thyroid hormone receptor responsible for polychlorinated biphenylmediated suppression of its action in vitro," Environmental Health Perspectives, vol. 116, no. 9, pp. 1231-1236, 2008.

[95] A. L. S. Dowling, G. U. Martz, J. L. Leonard, and R. T. Zoeller, "Acute changes in maternal thyroid hormone induce rapid and transient changes in gene expression in fetal rat brain," Journal of Neuroscience, vol. 20, no. 6, pp. 2255-2265, 2000.

[96] R. T. Zoeller and K. M. Crofton, "Thyroid hormone action in fetal brain development and potential for disruption by environmental chemicals," NeuroToxicology, vol. 21, no. 6, pp. 935-945, 2000.

[97] R. T. Zoeller, R. Bansal, and C. Parris, "Bisphenol-A, an environmental contaminant that acts as a thyroid hormone receptor antagonist in vitro, increases serum thyroxine, and alters RC3/neurogranin expression in the developing rat brain," Endocrinology, vol. 146, no. 2, pp. 607-612, 2005.

[98] H. F. Escobar-Morreale, M. J. Obregon, F. Escobar del Rey, and G. Morreale de Escobar, "Replacement therapy for hypothyroidism with thyroxine alone does not ensure euthyroidism in all tissues, as studied in thyroidectomized rats," Journal of Clinical Investigation, vol. 96, no. 6, pp. 2828-2838, 1995. 


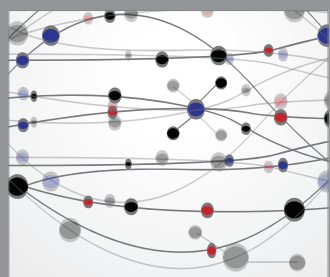

The Scientific World Journal
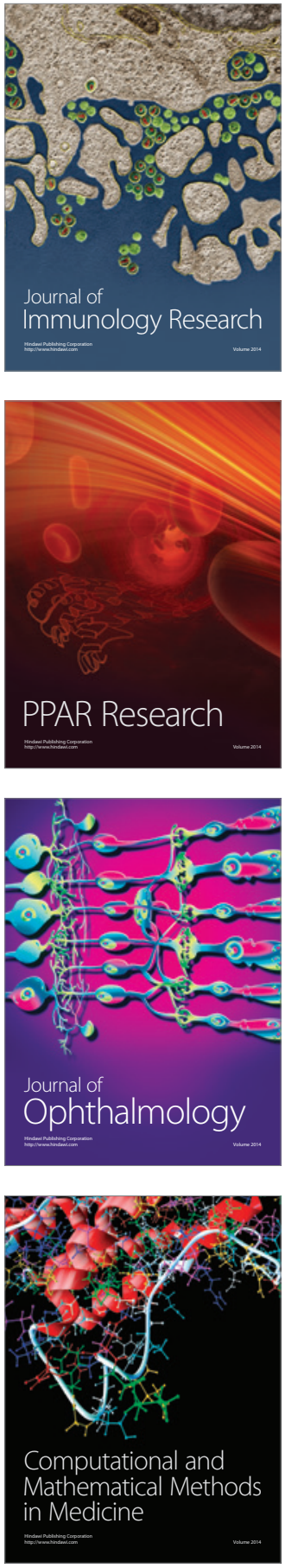

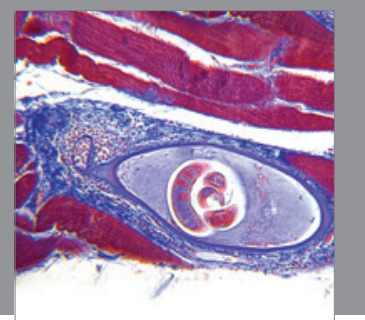

Gastroenterology

Research and Practice
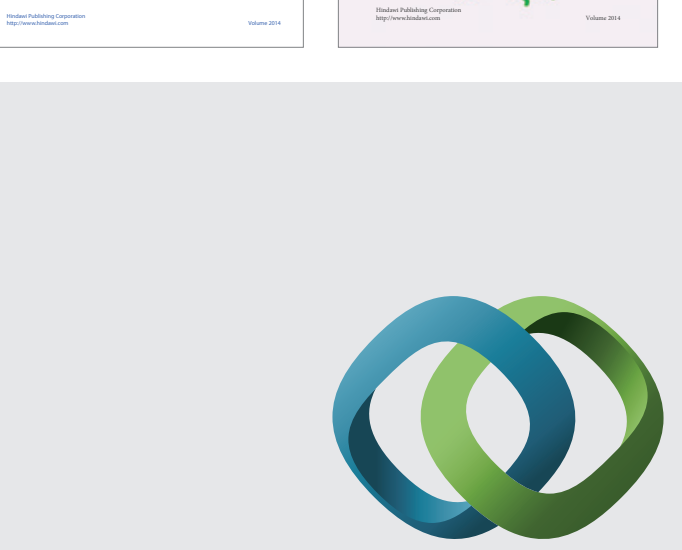

\section{Hindawi}

Submit your manuscripts at

http://www.hindawi.com
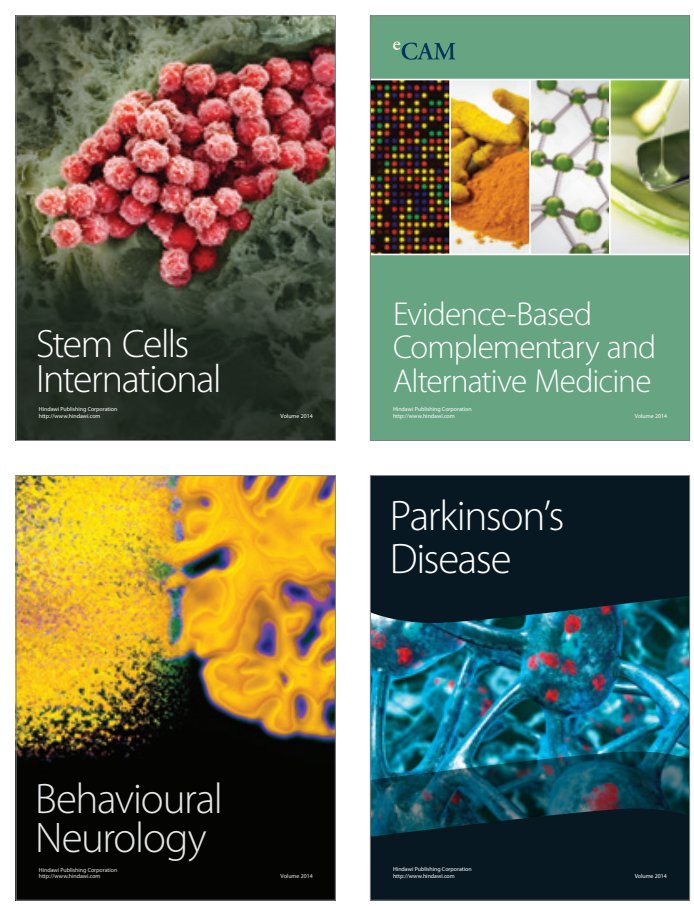

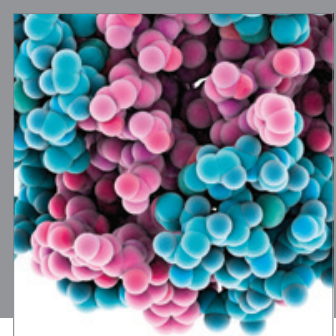

Journal of
Diabetes Research

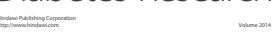

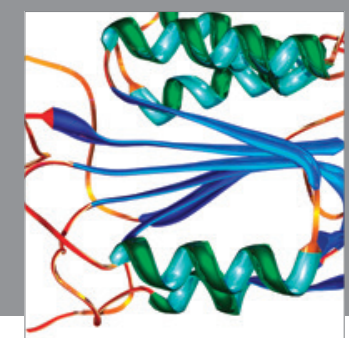

Disease Markers
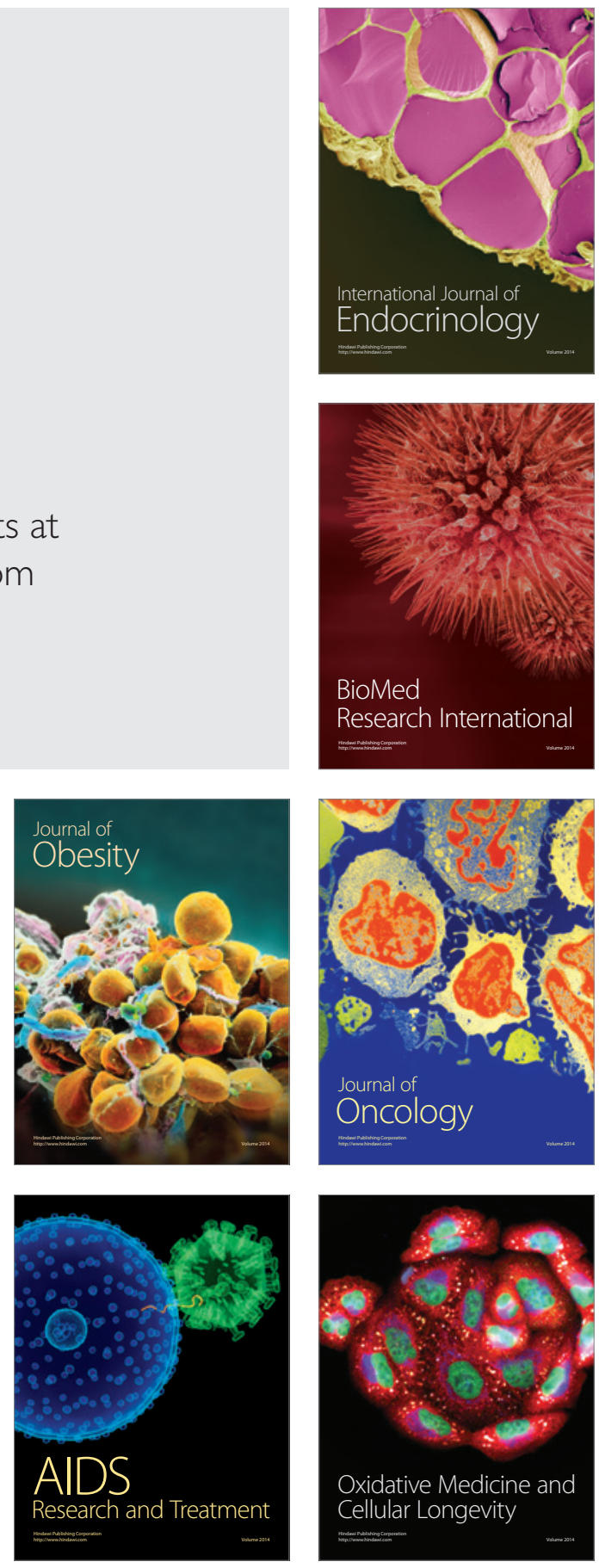